\title{
Dynamic SOC Compensation of an Ultracapacitor Module for a Hybrid Energy Storage System
}

\author{
Hyun-Sik Song*, Jin-Beom Jeong**, Dong-Hyun Shin***, Baek-Haeng Lee**, Hee-Jun Kimª and Hoon Heo ${ }^{\dagger}$ \\ $\dagger^{*}$ Dept. of Control and Instrumentation Engineering, Korea University, Seoul, Korea \\ ** Korea Automotive Technology Institute, Cheonan, Korea \\ *** Dept. of Mechatronics Engineering, Hanyang University, Seoul, Korea \\ $\ddagger$ Dept. of Electronic Systems Engineering, Hanyang University, Ansan, Korea
}

\begin{abstract}
The ultracapacitor module has recently been recast for use in hybrid energy storage systems (HESSs). As a result, accurate state-of-charge (SOC) estimation for an ultracapacitor module is as important as that of primary sources in order to be utilized efficiently in an energy storage system (ESS). However, while SOC estimation via the open-circuit voltage (OCV) method is generally used due to its linear characteristics compared with other ESSs, this method results in many errors in cases of highcurrent charging/discharging within a short time period. Accordingly, this paper introduces a dynamic SOC estimation algorithm that is capable of SOC compensation of an ultracapacitor module even when there is a current input and output. A cycle profile that simulates the operating conditions of a mild-HEV was applied to a vehicle simulator to verify the effectiveness of the proposed algorithm.
\end{abstract}

Key Words: Auxiliary energy system, Hybrid energy storage system, Ultracapacitor module, SOC compensation, State-of-Charge

\section{INTRODUCTION}

The energy storage systems (ESSs) for HEV, Plug-in HEV, and EV must be sized so that they can store sufficient energy and provide adequate peak power for a specified acceleration performance. They also need to have the ability to meet appropriate driving cycles. In addition, the energy storage devices must meet appropriate cycle and calendar life requirements [1]. According to these requirements, ESSs with high power and high energy, such as Ni-MH, Li-Ion and even leadacid batteries for mild-HEV, have been developed and are being used. However, Ni-MH, Li-ion, and lead-acid batteries alone, integrated into the vehicular power train, are not always sufficient to supply vehicle propulsion power and they are not able to accept energy from regenerative braking. Thus, the capacities of such batteries should eventually be over-designed in order to provide peak power demands. For this reason, these vehicles may use an ultracapacitor module (bank) as a part of their auxiliary energy system (AES) that is able to receive regenerated energy and provide power during peak periods.

An ultracapacitor, also known as a supercapacitor, an electric double layer capacitor (EDLC), or a pseudocapacitor, uses electrodes with an extremely large surface area, along with

\footnotetext{
Manuscript received Feb. 16, 2010; revised Jul. 22, 2010

$\dagger$ Corresponding Author: heo257@korea.ac.kr

Tel: +82-2-3290-3974, Fax: +82-2-929-7808, Korea Univ.

* Dept. of Control and Instrumentation Engineering, Korea University, Korea

** Korea Automotive Technology Institute, Korea

*** Dept. of Mechatronics Engineering, Hanyang University, Korea

$\ddagger$ Dept. of Electronic Systems Engineering, Hanyang University, Korea
}

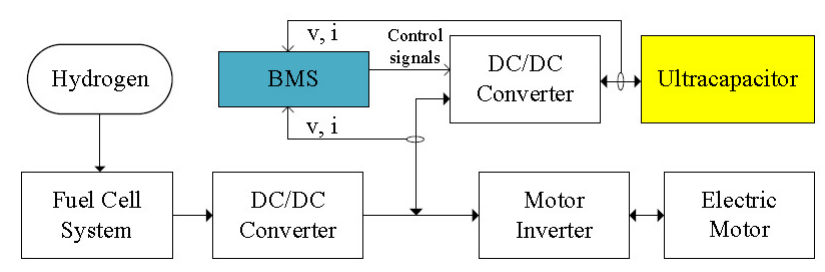

Fig. 1. Hybrid Fuel Cell - Ultracapacitor ESS.

electrolytes that can permit values of up to several thousand Farads per cell. Therefore, ultracapacitors have approximately 10-times the power density of a similar-sized battery, along with the ability to be being charged and discharged over 100times faster than a normal battery. Also, ultracapacitors have a very long life span [7],[8].

Throughout the world, research has been conducted on hybrid energy storage systems (HESSs), which simply mean an ESS containing both a battery or fuel cell and an ultracapacitor, such as a Hybrid Fuel Cell-Ultracapacitor ESS or Hybrid Battery-Ultracapacitor ESS [2]-[6]. Fig. 1 and 2 show the layout of a HESS with an ultracapacitor module.

In order to effectively use not only a battery but also an ultracapacitor module as a HESS, an accurate state-ofcharge (SOC) estimation must be performed using a battery management system (BMS) that manages and monitors the ESS. SOC estimation is one of the most important issues for application products that utilize an ESS. There are two 


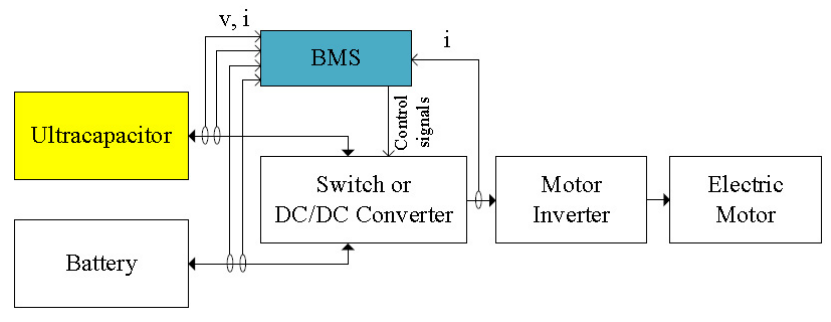

Fig. 2. Hybrid Battery - Ultracapacitor ESS.

well-known methods for SOC estimation of an ESS. One uses voltage, and the other uses current [9].

The voltage method uses the correlation between the SOC and the ESS voltage during charging and discharging. Although this method provides an accurate SOC based on the open-circuit voltage (OCV) after a sufficient time period for stabilization, different results are produced depending on the ambient temperature, the discharge rate (C-rate), the usage time, and variations in the characteristics of the ESS's internal resistance.

The current method also referred to as "Coulomb counting" or "ampere-hour counting" calculates the SOC by integrating the ESS's input and output currents. However, this method requires that an accurate account of the initial capacity and the current leakage, along with the sensing error, be accumulated over time, gradually increasing the SOC error.

Since precise SOC estimation is difficult using the aforementioned methods, new approaches such as Kalman filtering, Fuzzy logic, and a Support Vector Machine (SVM) have been proposed [10]-[12]. However, they call for model parameter accuracy. There are also drawbacks such as requiring a significant amount of testing data and the increased costs associated with using 32-bit MCUs for fast numerical processing. Therefore, an accurate SOC estimation requires research efforts that utilize the advantages of each method and do not use relatively large amounts of testing data, while taking cost into consideration.

In a HESS, an ultracapacitor module is usually used as an auxiliary power source due to its outstanding power characteristics. Moreover, the efficiency of an ESS can be improved, and its usage prolonged, by controlling the switch or bidirectional DC/DC converter according to the SOC of the ultracapacitor module [2],[3],[5],[11],[13]. Therefore, in addition to a battery's SOC accuracy, the SOC estimation of an ultracapacitor module, which involves a relatively small capacitance, enabling an easy change in the SOC even with small amounts of input and output current, is most important for applying a switch or DC/DC converter control logic.

The conventional approaches of calculating the SOC of an ultracapacitor module include an ampere-hour counting method that integrates the input and output current, and an OCV detection method that detects the ultracapacitor module's voltage, with no current flowing under a sufficiently stable state, in order to estimate the SOC value that corresponds to the detected voltage. However, since an ultracapacitor module has a much smaller capacitance than a battery, even a minute current error results in the accumulation of SOC

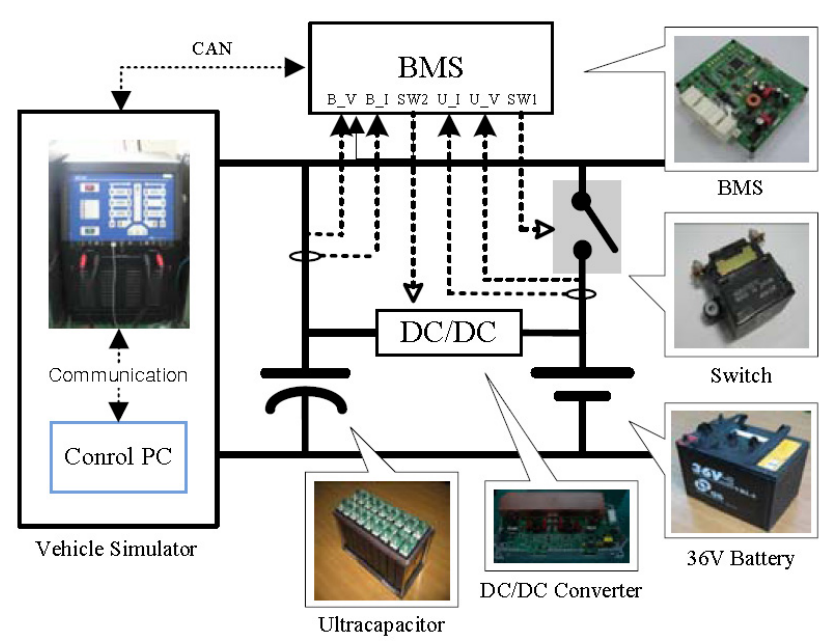

Fig. 3. The system configuration of HESS with ultracapacitor

TABLE I

ELECTRICAL CHARACTERISTICS OF THE ULTRACAPACITOR MODULE

\begin{tabular}{|c|c|c|c|}
\hline Rated Voltage & Rated Capacity & DC ESR & $\begin{array}{c}\text { Available } \\
\text { Energy }\end{array}$ \\
\hline $42[\mathrm{~V}]$ & $94.5[\mathrm{~F}]$ & $7.5[\mathrm{~m} \Omega]$ & $0.41[\mathrm{Ah}]$ \\
\hline
\end{tabular}

errors with the ampere-hour counting method. As for the OCV detection method, accurate SOC estimation is feasible only if measurement is made after the ultracapacitor module has been stabilized. SOC estimation based on voltage measurements while input or output current is present is prone to errors.

In order to perform an accurate SOC estimation for an ultracapacitor module in a HESS, this paper proposes an accurate SOC estimation algorithm that can be compensated during vehicle operation. It primarily uses ampere-hour counting, and when the ignition key (IG) is turned on, an initial SOC compensation is carried out according to the OCV, as is a voltage-based SOC compensation in the operation region determined through testing. The accuracy and effectiveness of the proposed algorithm was tested and verified using a vehicle simulator utilizing a cycle profile that simulates the driving conditions of mild-HEV.

\section{SYSTEM CONFIGURATION AND SPECIFICATION}

The HESS of the mild-HEV used for this study consists of an ultracapacitor module, a 36V VRLA (Valve Regulated Lead-Acid) battery, a switch, a DC/DC converter, and a BMS, as shown in Fig. 3. The ultracapacitor module consists of 18 serial-connected $1700 \mathrm{~F}$ cells, supplied by NESSCAP, and its electrical characteristics are described in Table I [2],[15].

The ultracapacitor module is always connected to a $42 \mathrm{~V}$ power net and used independently. When high energy is required for cranking or starting after an idle-stop, the BMS controls the switch for parallel operation with the battery according to the SOC of the VRLA battery and the ultracapacitor module, as well as the mode of the vehicle control unit (VCU). During regenerative braking and vehicle acceleration, the energy of the ultracapacitor module is transferred to the battery in advance so that it can receive more energy. In the 
case of a power assist, the switch or DC/DC converter is controlled in order to transfer energy to the battery.

The main function of the BMS controller is to calculate the SOC of the ultracapacitor module and VRLA battery in order to estimate the SOC of the HESS. For this reason, the BMS controller measures the current, the voltage, and the temperature required to calculate the SOC, transfers the HESS's available discharge and charge energy to the VCU, and manages the energy by controlling the switch.

Taking into consideration the cost and interface aspects, the current was measured using a Nikkohm $0.1 \mathrm{~m} \Omega$ shunt resistor by amplifying the voltage across two shunt terminals. The voltage was dropped to a $5 \mathrm{~V}$ level through resistance distribution. The temperature was measured using an NTC type thermistor, which is $10 \mathrm{k} \Omega$ at $25^{\circ} \mathrm{C}$. Since the current and voltage are closely related to an accurate SOC estimation, a 16-bit ADC was used for increased precision. An information exchange between the BMS and VCU was implemented based on CAN2.0B. An Infineon 16-bit XC164CS controller was used for the vehicle application for fast algorithm computation.

\section{SOC COMPENSATION}

Accurate SOC estimation of an ultracapacitor module that involves a relatively small capacitance, enabling an easy change in the SOC even with small amounts of input and output current, is extremely important, as is a battery's SOC accuracy. Therefore, this paper proposes an algorithm that uses an ampere-hour counting method, but compensates the initial SOC with the OCV, and further compensates for the current integration error by using the relationship between voltage detection in a specified low-current region and the SOC-OCV. The SOC compensation described above shall be referred to as "dynamic SOC compensation" in this paper.

\section{A. Initial SOC compensation}

Accurate SOC estimation for a vehicle based on OCV is feasible when sufficient time has passed for stabilization after battery usage, and when all of the loads are open. For this reason, experiments regarding the SOC-OCV relationship must be conducted in advance when charging or discharging at different temperatures, and the resulting data must be compiled in the nonvolatile memory of the BMS. The stabilization time for the SOC-OCV experiment is applied for 30 minutes by considering the worst case conditions in this paper. Fig. 4 displays the SOC-OCV curves for charging and discharging at various temperatures. As the graph indicates, there are discrepancies in the SOC-OCV relationship for charging and discharging depending on the temperature.

For the initial SOC compensation, the stabilization time after the IG is turned off and before it is turned back on is first checked. When the IG is turned off, the BMS stores the SOC based on ampere-hour counting and the time based on the real-time clock (RTC) in the flash memory, and the power is then turned off. When the IG is turned on, the BMS measures the voltage of the ultracapacitor module and the ambient temperature, and retrieves the $\mathrm{SOC}_{\mathrm{OCV}}$, which corresponds to the voltage and temperature from the look-up

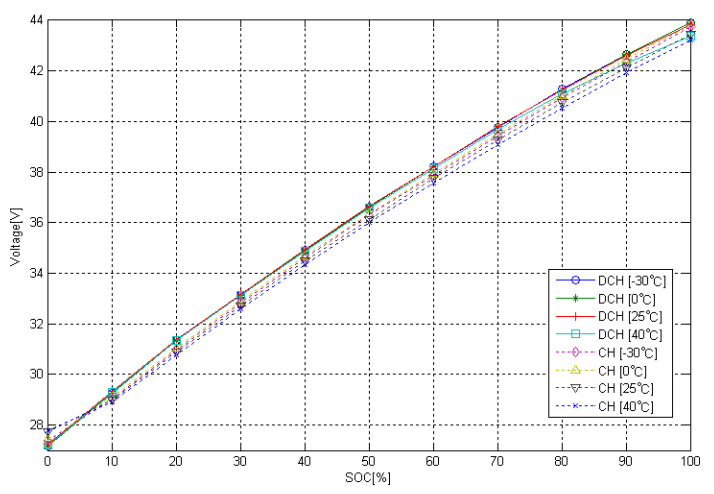

Fig. 4. Ultracapacitor module's SOC-OCV curves for charging /discharging at various temperatures.

table. The BMS then compares the RTC stored in the flash memory and the present RTC to determine the time required to stabilize the ultracapacitor module.

If sufficient time for stabilization has not yet passed, the BMS determines that the ultracapacitor module is not stable and uses the $\mathrm{SOC}_{\text {Flash }}$ stored in the flash memory as the initial $\mathrm{SOC}_{\text {Initial. }}$. If sufficient time has passed, the BMS determines that the ultracapacitor module is stabilized and uses the $\mathrm{SOC}_{\mathrm{OCV}}$ based on the OCV as the initial $\mathrm{SOC}_{\text {Initial }}$.

The $\mathrm{SOC}_{\text {Initial }}$ determined by the BMS is the initial SOC used for ampere-hour counting. As indicated by equations (4) and (5), since the capacitance of the ultracapacitor module is continuously integrated, the SOC (\%) is converted into capacity (Ah) according to equation (1).

$$
\mathrm{AH}_{\text {Initial }}=\frac{\mathrm{SOC}_{\text {Initial }} \times \mathrm{C}_{r}}{100}
$$

where, $\mathrm{C}_{\mathrm{r}}$ is the rated capacity that was tested by discharging from a fully charged condition (44V) to the cutoff voltage $(27 \mathrm{~V})$ through a constant current $(4 \mathrm{~A})$.

Fig. 5 illustrates the flow chart for obtaining $\mathrm{SOC}_{\text {Initial }}$.

\section{B. Dynamic SOC compensation}

If the input/output current has been maintained at 0 for a certain period of time for stabilization, or if the input/output current is not 0 but the current is below a specific value during charging/discharging, the dynamic SOC compensation of an ultracapacitor module involves calculating the $\mathrm{SOC}_{\mathrm{V}}$ based on the voltage and comparing it to the $\mathrm{SOC}_{\mathrm{AH}}$, which is calculated according to ampere-hour counting to provide compensation.

Therefore, it is necessary to conduct charging and discharging tests for the current levels in order to determine how much input/output current should flow through the ultracapacitor module for a sufficiently small voltage error, which is the difference in voltage before and after a rest time, and to determine the discrepancy in the SOC value that corresponds to the voltage error. It is also necessary to check at what point compensation should commence when a conversion is made during charging/discharging under the current threshold.

For the first experiment, charging/discharging was performed at a predetermined current level for a specific duration 


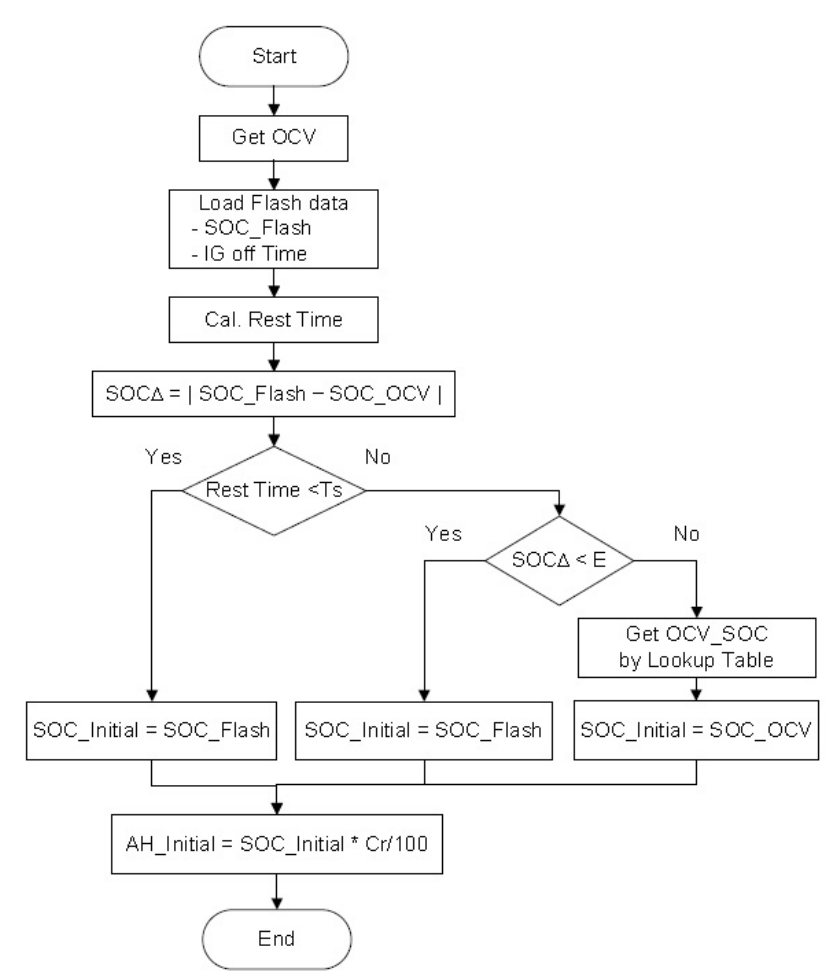

Fig. 5. Flow chart for calculating the initial capacity.

TABLE II

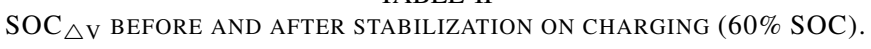

\begin{tabular}{|c|c|c|c|c|}
\hline $\begin{array}{c}\text { Test } \\
\text { Current } \\
{[\mathrm{A}]}\end{array}$ & $\begin{array}{c}\text { Voltage } \\
\text { @ 5sec } \\
{[\mathrm{V}]}\end{array}$ & $\begin{array}{c}\text { Voltage } \\
\text { @ 30 min } \\
{[\mathrm{V}]}\end{array}$ & $\begin{array}{c}\text { Voltage } \\
\text { difference } \\
{[\mathrm{V}]}\end{array}$ & $\begin{array}{c}\text { SOC } \triangle \mathrm{V} \\
{[\%]}\end{array}$ \\
\hline+2.5 & 38.62 & 38.60 & -0.02 & -0.13 \\
\hline+5.0 & 38.86 & 38.78 & -0.08 & -0.51 \\
\hline+7.5 & 39.08 & 38.94 & -0.14 & -0.90 \\
\hline+10 & 39.26 & 39.10 & -0.16 & -1.04 \\
\hline
\end{tabular}

( 5 seconds), and the voltage was measured after stabilization (30 minutes) in order to select an appropriate current level that produces a small error. The experiment was conducted with an SOC of $60 \%$ at an ambient temperature of $25^{\circ} \mathrm{C}$ for $2.5 \mathrm{~A}, 5 \mathrm{~A}$, 7.5A, and $10 \mathrm{~A}$ of test current. Detailed experimental results are shown in Tables II and III.

The $\mathrm{SOC}_{\Delta \mathrm{V}}$, which corresponds to the voltage difference before and after stabilization, can be obtained from equations (2) and (3).

$$
\mathrm{SOC}_{\Delta \mathrm{V}}=\frac{\frac{1}{2} \mathrm{C}\left(\mathrm{V}_{\mathrm{rest}}^{2}-\mathrm{V}_{\text {test }}^{2}\right)}{\mathrm{E}} \times 100
$$

TABLE III

$\mathrm{SOC}_{\triangle \mathrm{V}}$ BEFORE AND AFTER STABILIZATION ON DISCHARGING $(60 \%$ SOC).

\begin{tabular}{|c|c|c|c|c|}
\hline $\begin{array}{c}\text { Test } \\
\begin{array}{c}\text { Current } \\
{[\mathrm{A}]}\end{array}\end{array}$ & $\begin{array}{c}\text { Voltage } \\
\text { @ 5sec } \\
{[\mathrm{V}]}\end{array}$ & $\begin{array}{c}\text { Voltage } \\
@ 30 \mathrm{~min} \\
{[\mathrm{~V}]}\end{array}$ & $\begin{array}{c}\text { Voltage } \\
\text { difference } \\
{[\mathrm{V}]}\end{array}$ & $\begin{array}{c}\text { SOC } \triangle \mathrm{V} \\
{[\%]}\end{array}$ \\
\hline-2.5 & 38.44 & 38.50 & 0.06 & 0.38 \\
\hline-5.0 & 38.42 & 38.50 & 0.08 & 0.51 \\
\hline-7.5 & 38.42 & 38.52 & 0.10 & 0.64 \\
\hline-10 & 38.36 & 38.52 & 0.16 & 1.02 \\
\hline
\end{tabular}

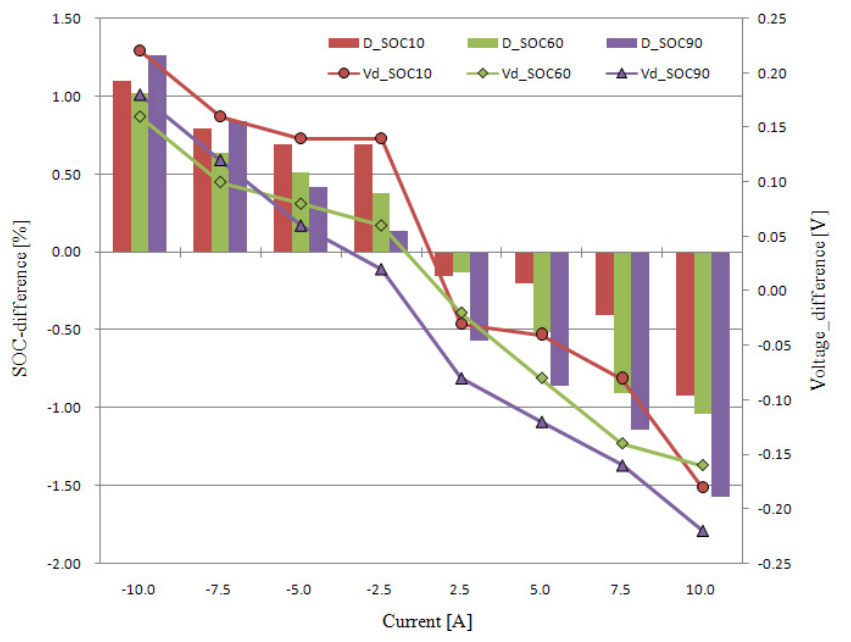

Fig. 6. SOC difference corresponding to the voltage difference before and after stabilization according to test current levels.

TABLE IV

SOC DIFFERENCE DUE TO THE CURRENT AND TIME

\begin{tabular}{|c|c|c|c|c|c|}
\hline \multirow{3}{*}{$\begin{array}{c}\text { Initial } \\
\text { Current } \\
{[\mathrm{A}]}\end{array}$} & $\begin{array}{c}\text { Test } \\
\text { Current } \\
{[\mathrm{A}]}\end{array}$ & \multicolumn{4}{|c|}{ SOC difference [\%] } \\
\cline { 3 - 6 } & & $3 \mathrm{sec}$ & $5 \mathrm{sec}$ & $7 \mathrm{sec}$ & $10 \mathrm{sec}$ \\
\hline \multirow{4}{*}{150} & 5 & 3.57 & 3.35 & 3.24 & 3.25 \\
\cline { 2 - 6 } & 2.5 & 3.09 & 3.1 & 2.86 & 2.87 \\
\cline { 2 - 6 } & 0 & 2.97 & 2.85 & 2.61 & 2.49 \\
\cline { 2 - 6 } & -2.5 & -2.48 & -2.48 & -2.36 & -2.12 \\
\cline { 2 - 6 } & -5 & -2.6 & -2.23 & -1.99 & -1.74 \\
\hline \multirow{4}{*}{-250} & 5 & 3.22 & 3.01 & 2.7 & 2.6 \\
\cline { 2 - 6 } & 2.5 & 3.41 & 3.31 & 3.0 & 2.79 \\
\cline { 2 - 6 } & 0 & 3.61 & 3.4 & 3.3 & 3.19 \\
\cline { 2 - 6 } & -2.5 & 3.82 & -3.71 & -3.59 & -3.37 \\
\cline { 2 - 6 } & -5 & -3.92 & -3.8 & -3.79 & -3.66 \\
\hline
\end{tabular}

$$
\mathrm{E}=\frac{1}{2} \mathrm{C}\left(\mathrm{V}_{\max }^{2}-\mathrm{V}_{\min }^{2}\right)
$$

where, $\mathrm{C}$ is the capacitance of 18 serially-connected $1700 \mathrm{~F}$ capacitors, $V_{\text {rest }}$ is the voltage after stabilization, $V_{\text {test }}$ is the voltage at the termination of the experiment with a corresponding current, $\mathrm{V}_{\max }$ is the fully charged voltage, $\mathrm{V}_{\min }$ is the cutoff voltage, and $\mathrm{E}$ is the difference in energy between the maximum energy at the fully-charged voltage and the minimum energy at the cutoff voltage.

$\mathrm{E}$ is 56997.22 from equation (3). In the case of the $5 \mathrm{~A}$, $5 \mathrm{sec}$ experiment shown in Table II, the $\mathrm{SOC}_{\Delta \mathrm{V}}$ before and after stabilization is $0.51 \%$ from equation (2).

The test results indicate that the SOC difference is proportional to the current, producing errors at around $0.5 \%$ and $1 \%$ at $\pm 5 \mathrm{~A}$ and $\pm 10 \mathrm{~A}$, respectively.

In order to examine whether the SOC difference displayed similar tendencies outside of the $60 \%$ SOC region, additional tests were conducted for a $10 \%$ SOC and a $90 \%$ SOC. As shown in Fig. 6, the $10 \%$ SOC difference was smaller than the others for charging, but bigger than the others for 5A below the discharging region. It was also found that the SOC ratio for the voltage difference before and after stabilization for $5 \mathrm{~A}$ of charging/discharging was less than $\pm 1 \%$.

Applying the results of the first test is problematic because there is no time for stabilization during actual vehicle operation. Therefore, in order to find a region that allows 
for compensation during operation, a second experiment was conducted to examine whether the SOC comes within a desired error range if the test current $(0, \pm 2.5 \mathrm{~A}, \pm 5 \mathrm{~A})$ is maintained for a few seconds after the maximum charging/discharging. Taking into consideration the operating conditions of a mildHEV (5kW cranking and regenerative braking of $3.3 \mathrm{~kW}[2]$ ), the maximum range of the charging/discharging current that can be applied to an ultracapacitor module was set at $150 \mathrm{~A}$ for charging and 250A for discharging.

Table IV lists the SOC differences for voltage differences after charging for 5 seconds at $150 \mathrm{~A}$ from a cutoff voltage of $27 \mathrm{~V}$; discharging for 4 seconds at $250 \mathrm{~A}$ from a fullycharged voltage of $44 \mathrm{~V}$; maintaining the charge/discharge for 3, 5, 7 and 10 seconds at the test current; and after undergoing stabilization. The experimental results indicate that if the test current flows in the same direction as the initial current, the voltage difference becomes greater than in the case of the opposite direction. It can be deduced that the maximum difference would occur with $5 \mathrm{~A}$ of current flowing in the same direction as the initial current, and that the average SOC difference would be around 3\%. Therefore we set the stabilization current below $\pm 5 \mathrm{~A}$ for dynamic SOC compensation.

The SOC difference caused by the maximum voltage difference (initial current : $-250 \mathrm{~A}$, test current: $2.5 \mathrm{~A}$ ) that can occur with the current maintained below $\pm 5 \mathrm{~A}$ decreases by up to $0.52 \%$ as the duration of the current held below $\pm 5 \mathrm{~A}$ is increased from 5 to 10 seconds. However, the difference is not significant. Since designing the algorithm in such a way that SOC compensation occurs only when the duration of the current held below $\pm 5 \mathrm{~A}$ exceeds 10 seconds reduces the number of SOC compensations, it is advisable to set the duration of the current maintenance at about 5 seconds.

Fig. 7 and 8 are voltage and current waveforms when the stabilization current is flowing in the same direction as the initial charging/discharging current generated when the SOC error is at its maximum. According to Fig. 7, when resting after charging at $150 \mathrm{~A}$ for 5 seconds, and then charging again at $5 \mathrm{~A}$ for another 5 seconds, the voltage at the end of the $5 \mathrm{~A}$ charge is $36.42 \mathrm{~V}$, which drops down to $35.86 \mathrm{~V}$ after 30 minutes of stabilization. Using equations (2) and (3), the SOC error becomes $3.35 \%$. Likewise, according to Fig. 8, when resting after discharging at $-250 \mathrm{~A}$ for 4 seconds and then discharging again at $-5 \mathrm{~A}$ for another 5 seconds, the voltage at the end of the $-5 \mathrm{~A}$ discharge is $31.48 \mathrm{~V}$, which increases to $32.30 \mathrm{~V}$ after 30 minutes of stabilization, yielding a SOC error of $-3.8 \%$.

In this study, if the current is maintained at $5 \mathrm{~A}$ or below for 5 seconds or longer, the present voltage of the ultracapacitor module is measured to obtain the $\mathrm{SOC}_{\mathrm{V}}$ based on the voltage. Compensation of the SOC only takes place when there is a difference of $5 \%$ or greater between the current value $\left(\mathrm{SOC}_{\mathrm{AH}}\right)$, calculated by ampere-hour counting, and the compensation target value $\left(\mathrm{SOC}_{\mathrm{V}}\right)$, calculated using the voltage. This takes into consideration the innate error (up to $3.8 \%$ ) of the compensation mechanism which uses the present voltage. However, if the $\mathrm{SOC}_{\mathrm{V}}$ based on the voltage is applied directly to the $\mathrm{SOC}_{\mathrm{C}}$ as the compensation SOC
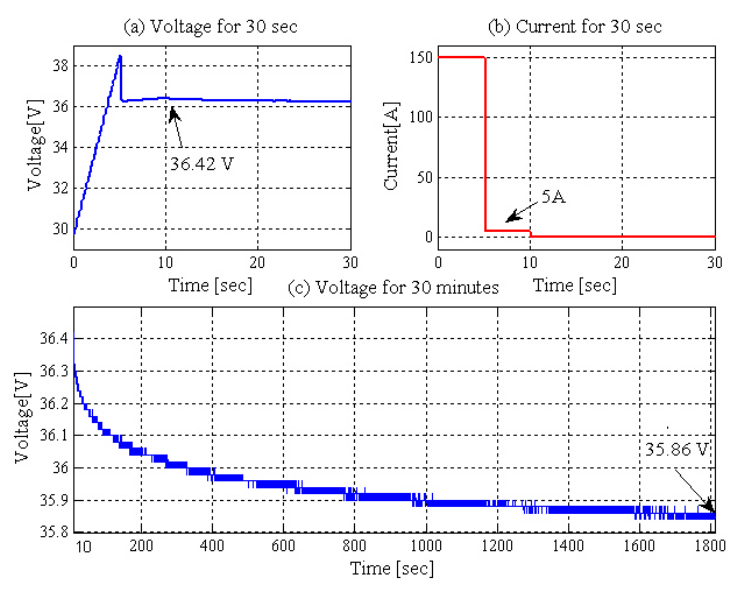

Fig. 7. Charging at $150 \mathrm{~A}$ followed by charging at $5 \mathrm{~A}$.
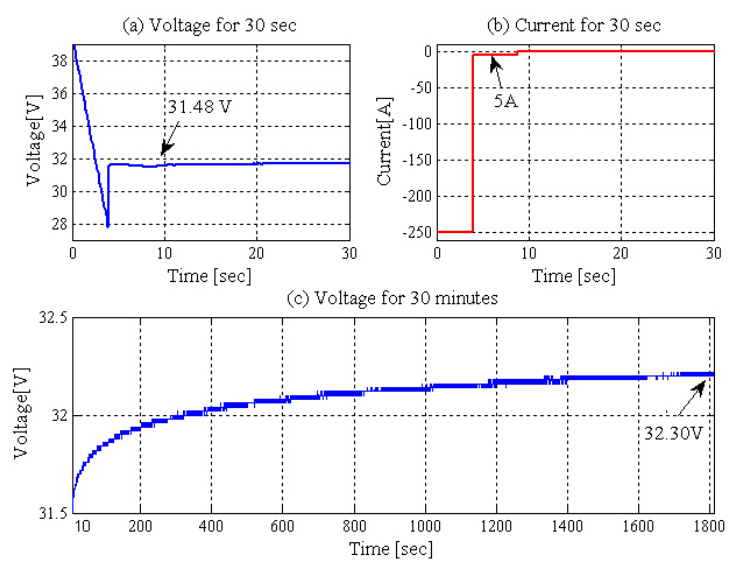

Fig. 8. Discharging at $250 \mathrm{~A}$ followed by discharging at $5 \mathrm{~A}$.

value, an instantaneous SOC variation can cause instability. Therefore, it would be appropriate to perform small levels of $(+)$ compensation during charging and $(-)$ compensation during discharging for a specified compensation time $\left(\Delta t_{C}\right)$ in a consistent manner.

The associated equations of a dynamic SOC compensation algorithm for the ultracapacitor module described earlier can be expressed as follows:

Step 1. After detection of the input/output current of the ultracapacitor module, calculate the $\mathrm{SOC}_{\mathrm{AH}}$ via ampere-hour counting.

$$
\mathrm{AH}_{\mathrm{t}}=\frac{\mathrm{AS}_{\mathrm{t}-1}+\mathrm{i}_{\mathrm{t}} \times \mathrm{t}_{\mathrm{s}} \times \mathrm{f}_{\mathrm{e}}}{3600}
$$

Here, $\mathrm{AH}_{\mathrm{t}}$ is the ampere-hour ( $\mathrm{Ah}$ ) accumulated up to the present moment, $\mathrm{AS}_{\mathrm{t}-1}$ is the ampere-sec (As) accumulated up to the previous point, $i_{t}$ is the amount of current at the present moment, $t_{s}$ is the sampling time, and $f_{e}$ is the charging/discharging efficiency.

$$
\mathrm{SOC}_{\mathrm{AH}}=\frac{\mathrm{AH}_{\text {Initial }}+\mathrm{AH}_{\mathrm{t}}}{\mathrm{C}_{\mathrm{r}}} .
$$

Here, $\mathrm{AH}_{\text {Initial }}$ is the initial capacity when the ignition key is turned on, and $\mathrm{C}_{\mathrm{r}}$ is the rated capacitance. 
Step 2. If the magnitude of the input/output current $\left(\left|i_{\text {cap }}\right|\right)$ is less than a predefined value $(\Delta \mathrm{i})$, check if the current is maintained for a specified duration $(\Delta \mathrm{t})$.

Step 3. If the magnitude of the current is maintained for a specified duration $(\Delta t)$, calculate the $\mathrm{SOC}_{\mathrm{V}}$ based on the voltage of the ultracapacitor module from the SOC-OCV table.

Step 4. Calculate the error of the remaining capacity with the present $\mathrm{SOC}_{\mathrm{AH}}$ and the $\mathrm{SOC}_{\mathrm{V}}$ based on the voltage.

$$
\mathrm{SOC}_{\text {error }}=\mathrm{SOC}_{\mathrm{AH}}-\mathrm{SOC}_{\mathrm{V}} \text {. }
$$

Step 5. If the error of the remaining capacity is greater than the predefined error range $( \pm 5 \%)$, set the $\mathrm{SOC}_{\mathrm{V}}$ as the remaining capacity $\left(\mathrm{SOC}_{\mathrm{C}}\right)$ and perform continuous compensation for the accumulated error of the $\mathrm{SOC}_{\mathrm{AH}}$ over a specified compensation time $\left(\Delta t_{C}\right)$ in small amounts.

$$
\mathrm{SOC}_{\mathrm{C}}=\mathrm{SOC}_{\mathrm{AH}} \pm \frac{\mathrm{SOC}_{\text {error }}}{\Delta \mathrm{t}_{\mathrm{C}}} .
$$

Step 6. Update from the $\mathrm{SOC}_{\mathrm{C}}$ to the ASt.

$$
\mathrm{AS}_{\mathrm{t}}=\left(\frac{\mathrm{SOC}_{\mathrm{C}} \times \mathrm{C}_{\mathrm{r}}}{100}-\mathrm{AH}_{\text {Initial }}\right) \times 3600 .
$$

Step 7. When compensation for the $\mathrm{SOC}_{\text {error }}$ is complete, once again monitor whether the input/output current is maintained below a specified current $\operatorname{level}(\Delta \mathrm{i})$ for a specified duration $(\Delta \mathrm{t})$.

\section{EXPERIMENTS}

\section{A. Sensing accuracy test}

The proposed algorithm for the dynamic SOC compensation of an ultracapacitor module is based on the current, voltage, and temperature measured by the BMS. Accordingly, the sensing accuracy used by the BMS to calculate the SOC is important. Sensing errors in the current measurement totaled about $1 \%$ in the $-250 \mathrm{~A} \sim 150 \mathrm{~A}$ range, and about $2 \%$ in the low current range $(-10 \mathrm{~A} \sim 10 \mathrm{~A})$. The voltage errors were within $0.5 \%$ in the $27 \mathrm{~V} \sim 44 \mathrm{~V}$ region. As for temperature, the errors were within $3 \%$ between $-40^{\circ} \mathrm{C}$ and $90^{\circ} \mathrm{C}$.

In order to minimize the errors associated with the external environment, all of the tests were conducted in a chamber at $25^{\circ} \mathrm{C}$. For use as references to determine the accuracy of the algorithm explained below, we used a Yokogawa current transducer (751574), which is capable of measuring current with an error rate of less than $0.05 \%$, and a NetDAQ 2640 to measure the voltage within an error range of $0.01 \%$.

\section{B. SOC accuracy test}

There are generally no standard procedures for an accuracy test of SOC estimation during the development process of a BMS. Therefore, a manufacturer in the development of a BMS uses its own test procedure; it starts the test profile at a specific SOC in a state in which the capacity of the ESS is already known. It then discharges at the end of the test cycle until it reaches the cutoff voltage. Finally, the parameters are tweaked for SOC estimation if there is not an equally similar reference SOC for comparing the accuracy of the SOC

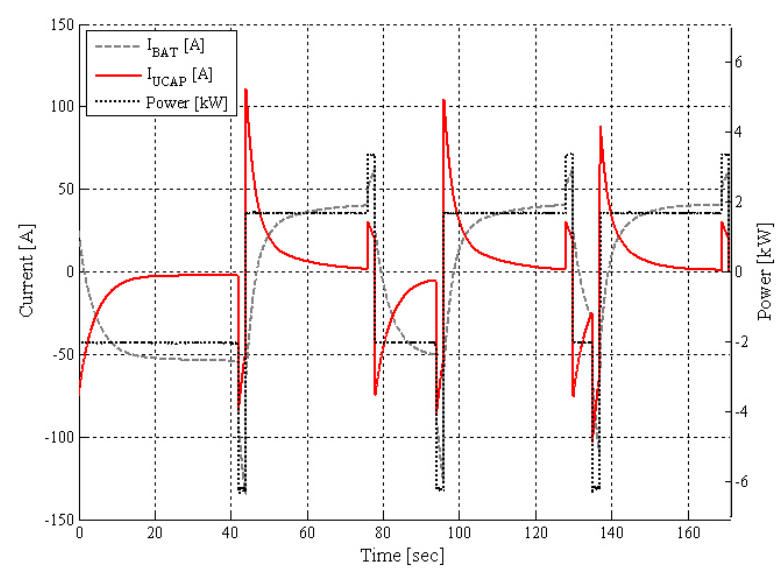

Fig. 9. Test cycle profile of ultracapacitor module.

estimation calculated in equation (9) and the last value of the SOC calculated by the BMS.

$$
\mathrm{SOC}_{\text {remain }}=\frac{\mathrm{AH}_{\mathrm{r}}}{\mathrm{C}_{\mathrm{r}}} \times 100
$$

where, $\mathrm{AH}_{\mathrm{r}}$ is the remaining capacity at the cutoff voltage, and $\mathrm{C}_{\mathrm{r}}$ is the rated capacity.

In order to examine how much the proposed algorithm affects the SOC accuracy of the ultracapacitor module of a HESS, a test profile reflecting the idle stop/start, regenerative braking, other phenomena that frequently occur during mildHEV driving, and the extract current $\left(\mathrm{I}_{\mathrm{ucap}}\right)$ of the ultracapacitor module from the parallel battery and the ultracapacitor module, was created as shown in Fig. 9 and put through a test of 100 cycles, after which the remaining capacity of the ultracapacitor module was checked. The original cycle profile was modified by adding a regenerative function to the ZPA (zero-power assist) efficiency and the life test profile from the "Freedom CAR 42V Battery Test Manual" published by INEEL and DOE [2],[14] .

The 100-cycle test was started after fully charging the ultracapacitor module and then discharging it for two hours down to $4 \mathrm{~A}$ and $60 \%$ of the SOC. The BMS measured the current, the voltage, and the temperature, and then it calculated the SOCs of the voltage, the ampere-hour, and the dynamic compensation every $10 \mathrm{~ms}$.

Fig. 10 shows the results of the SOC estimation at 1-, 10-, and 100-cycles, respectively. Figure (a) shows that all of the SOCs $\left(\mathrm{SOC}_{\mathrm{AH}}, \mathrm{SOC}_{\mathrm{V}}, \mathrm{SOC}_{\mathrm{C}}, \mathrm{SOC}_{\mathrm{Ref}}\right)$ are started under the same conditions and there is no critical SOC error in the first cycle. Figure (b) shows that the dynamic SOC compensation happens first based on the $\mathrm{SOC}_{\mathrm{V}}$ when the current is below $\pm 5 \mathrm{~A}$, and its condition is maintained for $5 \mathrm{~s}$ or more. Figure (c) shows that the error rate comparing the $\mathrm{SOC}_{\mathrm{AH}}$ and the $\mathrm{SOC}_{\mathrm{Ref}}$ is increased gradually owing to an accumulation of current sensing error that is dependent over time. However, the $\mathrm{SOC}_{\mathrm{C}}$ using the dynamic SOC estimation algorithm follows well the ampere-hour counting under a high current, and skillfully adjusts as a voltage method under a low current. 
TABLE V

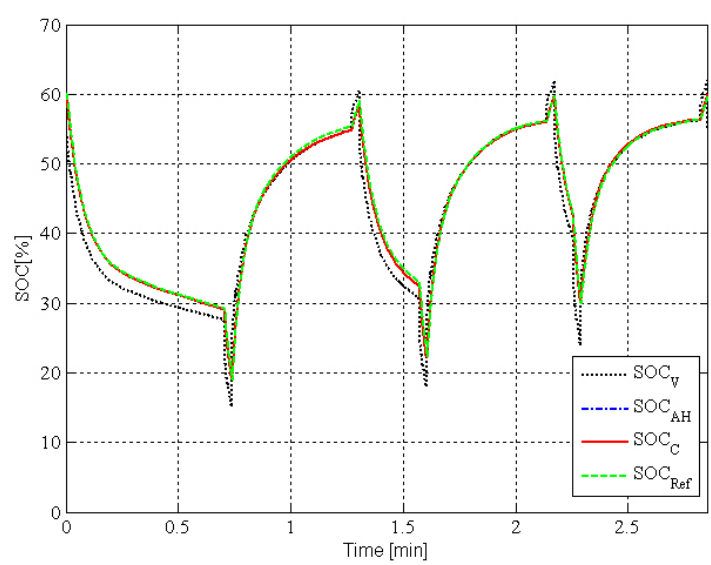

(a) 1 cycle.

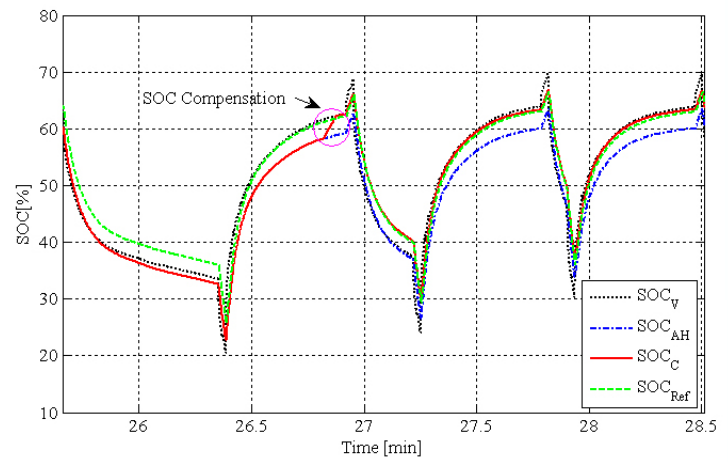

(b) 10 cycles.

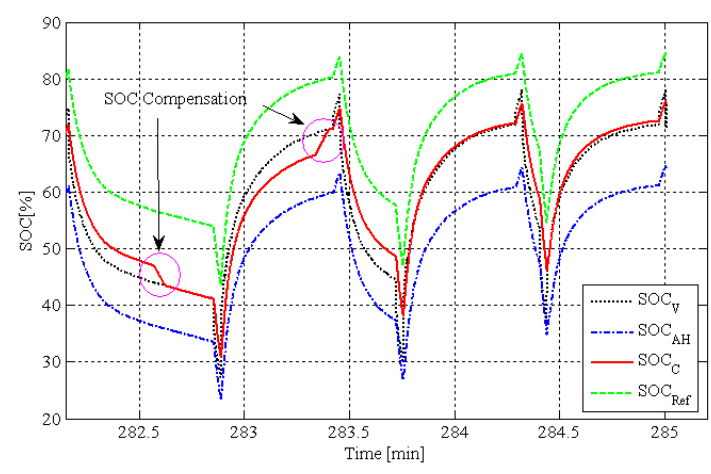

(c) 100 cycles.

Fig. 10. The results of SOC estimation.

When the test cycle was done, the ultracapacitor module was discharged at $4 \mathrm{~A}$ to the cutoff voltage in order to examine the remaining capacity $\left(\mathrm{SOC}_{\mathrm{remain}}\right)$, which is the reference accuracy of the SOC measured by a precision current sensor and data acquisition (DAQ). The SOC using the ampere-hour method was also calculated by using the current of the DAQ to compare the accuracy of the SOCs during each cycle.

Table $\mathrm{V}$ shows the accuracy results of the SOC estimation for the cycle test. According to the test results, the difference between the remaining capacity, taken after the cycle test was calculated using the reference, and the SOC of the dynamic compensation of the BMS was $2.96 \%$. This is within the general design specification of $\pm 5 \%$ in HEV applications. The
THE ACCURACY RESULTS OF SOC ESTIMATION FOR THE CYCLE TEST

\begin{tabular}{|c|c|c|c|c|c|}
\hline \multirow{2}{*}[\%]{} & \multicolumn{2}{|c|}{ Reference } & \multicolumn{3}{c|}{ BMS } \\
\cline { 2 - 6 } & SOC $_{\text {remain }}$ & SOC $_{\mathrm{AH}}$ & $\mathrm{SOC}_{\mathrm{V}}$ & $\mathrm{SOC}_{\mathrm{AH}}$ & $\mathrm{SOC}_{\mathrm{C}}$ \\
\hline SOC & 78.52 & 84.2 & 75.35 & 64.18 & 75.56 \\
\hline Error & - & 5.68 & 3.17 & 14.34 & 2.96 \\
\hline
\end{tabular}

results also show that it has a similar error rate when compared to the $\mathrm{SOC}_{\mathrm{V}}$, but a greater accuracy than the $\mathrm{SOC}_{\mathrm{AH}}$. Even if the difference in the SOC between the $\mathrm{SOC}_{\mathrm{V}}$ and the $\mathrm{SOC}_{\mathrm{C}}$ in the BMS is not large after the end of a cycle, the difference in the $\mathrm{SOC}$ between the $\mathrm{SOC}_{\mathrm{V}}$ and the $\mathrm{SOC}_{\mathrm{Ref}}$ is bigger under high-current situations such as engine starting and during the regenerative braking function of a HEV.

\section{CONCLUSIONS}

In order to improve the accuracy of the SOC estimation of an ultracapacitor module used in a HESS, this paper introduced a compensation algorithm that uses compensation by the OCV when the ignition key is turned on, as well as the ultracapacitor module voltage when the input/output current is below a certain level during operation. This study also verified the accuracy of the proposed dynamic SOC algorithm within $2.96 \%$ of the reference based on a modified cycle profile test that simulated mild-HEV driving conditions.

Even if the ultracapacitor module is modified in a HESS that uses the ultracapacitor module as a power source, dynamic SOC estimation can be accurately performed using a few sets of test data, as described in this paper.

\section{APPENDIX}

SOC : $\quad$ State-of- Charge

ESS : $\quad$ Energy Storage System

HESS : $\quad$ Hybrid Energy Storage System

HEV : Hybrid Electric Vehicle

BMS : $\quad$ Battery Management System

ZPA : Zero-Power Assist

ESR : $\quad$ Equivalent Series Resistance

\section{REFERENCES}

[1] Andrew F. Burke, "Batteries and ultracapacitors for electric, hybrid, and fuel cell vehicles," Proceeding of the IEEE, Vol. 95, No. 4, pp. 806-820, Apr. 2007.

[2] Baek-Haeng Lee, Dong-Hyun Shin, Hyun-Sik Song et al, "Development of an advanced hybrid energy storage system for hybrid electric vehicles," Journal of Power Electronics, Vol. 9, No. 1, 51-60, Jan. 2009.

[3] Adam W. Stienecker, Thomas Stuart, Cyrus Ashtiani, "An ultracapacitor circuit for reducing sulfation in lead acid batteries for Mild Hybrid Electric Vehicles," Journal of Power Sources, Vol. 156, pp. 755-762, Aug. 2005.

[4] Paul Bentley, David A. Stone, Nigel Schofield, "The parallel combination of a VRLA cell and supercapacitor for use as a hybrid vehicle peak power buffer,' Journal of Power Sources, Vol. 147, Issues 1-2, pp. 288-294, Sep. 2005.

[5] Cyrus Ashtiani, Randy Wright, Gary Hunt, "Ultracapacitors for automotive applications," Journal of Power Sources, Vol. 154, pp. 561-566, Dec. 2005.

[6] Liqing Sun, Ruchuan Liang, Qingcai Wang, and Feng Wei, "Design and simulation of FC plug-in hybrid bus with ultracapacitors," Journal of Asian Electric Vehicles, Vol. 5, No. 2, Dec. 2007.

[7] Do Yang Jung, Young Ho Kim, Sun Wook Kim, Suck-Hyun Lee, "Development of ultracapacitor modules for 42-V automotive electrical systems," Journal of Power Sources, Vol. 114, pp. 366-373, Oct. 2002. 
[8] Nesscap Co., Ltd, NESSCAP Ultracapacitor Technical Guide, 2008.

[9] Sabine Piller, Marion Perrin, Andeas Jossen, "Methods for state-ofcharge and their applications," Journal of Power Sources, Vol. 96, pp. 113-120, Jan. 2001.

[10] Seongjun Lee, Jonghoon Kim, Jaemoon Lee, B.H. Cho, "State-of-charge and capacity estimation of lithium-ion battery using a new open-circuit voltage versus state-of-charge," Journal of Power Sources, Vol 185, pp. 1367-1373, Sep. 2008.

[11] Dawei Gao, Zhenhua Jin, Qingchun Lu, "Energy management strategy based on fuzzy logic for a fuel cell hybrid bus," Journal of Power Sources, Vol. 185, pp. 311-317, Jul. 2008.

[12] Terry Hansen, Chia-Jiu Wang, "Support vector based battery state of charge estimator," Journal of Power Sources, Vol. 141, pp.351-358, Nov. 2004.

[13] Hosein Farzanehfard, Dawood Shekari Beyragh, Ehsan Adib, "A bidirectional soft switched ultracapacitor interface for hybrid electric vehicles," Energy Conversion and Management, Vol. 49, pp. 3578-3584, Aug. 2008.

[14] J. Barnes, FreedomCAR 42V Battery Test Manual, INEEL and DOE/ID11070, Apr. 2003.

[15] Hyun-Sik Song, Jin-Beom Jung, Baek-Haeng Lee, Dong-Hyun Shin et al., "A Study on the dynamic SOC compensation of an Ultracapacitor module for the Hybrid Energy Storage System," International Telecommunications Energy Conference, Oct. 2009.

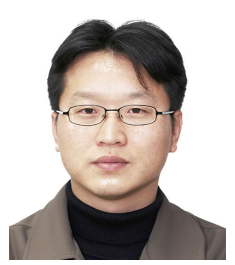

Hyun-Sik Song received his B.S. in Control and Instrumentation Engineering from the Korea Maritime University, Busan, Korea, in 2001 and his M.S. in Mechatronics Engineering from the Gwangju Institute of Science and Technology, Korea, in 2003. He is presently a Ph.D. candidate in the Department of Control and Instrumentation Engineering, Korea University, Seoul, Korea. His research interests are in BMS, switching power converters and HILS for PHEV/EVs. He is currently a Senior Researcher at the Electronic System R\&D Center of the Korea Automotive Technology Institute.

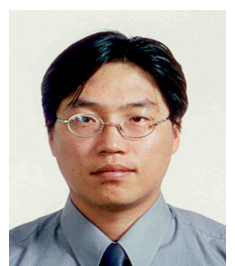

Jin-Beom Jeong received his B.S. and M.S. in Electrical Engineering from Hanyang University, Ansan, Korea, in 2001 and 2003, respectively, and his Ph.D. from the Department of Electronic, Electrical, Control and Instrumentation Engineering, Hanyang University, Korea, in 2007. Since 2007, he has been with the Electronic System R\&D Center, Korea Automotive Technology Institute (KATECH), Korea, where he is currently a Senior Researcher. His fields of interest include switching power converters, power electronic systems, BMS, battery systems, and EV/PHEV charging system.

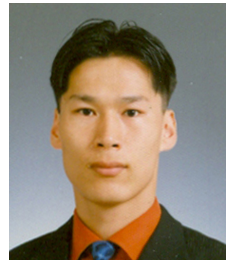

Dong-Hyun Shin received his B.S. in Mechanical Engineering from Sungkyunkwan University, Korea, in 1999 and his M.S. in Mechatronics Engineering from the Gwangju Institute of Science and Technology, Korea, in 2001. He is presently a Ph.D. candidate in the Department of Mechatronics Engineering, Hanyang University, Korea. His major fields of interest are the design of hybrid electric vehicles and the optimal control and modeling of energy storage systems. He is currently a Senior Researcher at the Electronic System R\&D Center of the Korea Automotive Technology Institute.

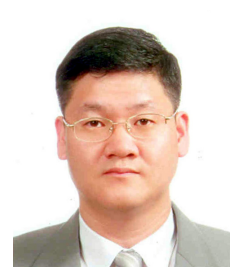

Baek-Haeng Lee received his B.S and M.S. in Electrical Engineering from Chung-Ang University, Seoul, Korea, in 1992 and 1994, respectively, and his Ph.D. from the Department of Electronic, Electrical, Control and Instrumentation Engineering, Hanyang University, Korea, in 2009. His research interests include power converters, energy storage devices and electronic ballasts. He is currently the Head of the Electronic System R\&D Center of the Korea Automotive Technology Institute.

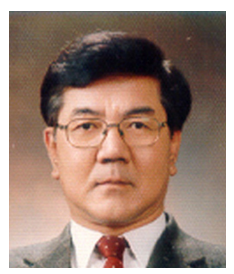

Hee-Jun Kim received his B.S and M.S. in Electronics Engineering from Hanyang University, Seoul, Korea, in 1976 and 1978, respectively, and his Ph. D. in Electronics Engineering from Kyushu University, Kyushu, Japan, in 1986. Since 1987, he has been with the Department of Electronic Systems Engineering, Hanyang University, Ansan, Korea, where he is currently a Professor. His fields of interest include switching power converters, electronic ballast, soft switching techniques, and analog signal processing. Dr. Kim is a Fellow of the Korean Institute of Electrical Engineers, the Institute of Electronics Engineer of Korea, and the Korean Institute of Power Electronics.

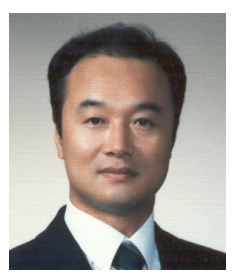

Hoon Heo received his B.S. in Mechanical Engineering from Korea University, Korea, in 1975, his M.S. in Aerospace Engineering from the University of Texas at Austin, USA, in 1981, and his Ph.D. in Mechanical Engineering from Texas Tech University, USA, in 1985. Since 1989, he has been with the School of Control and Instrumentation Engineering, Korea University, Seoul, Korea, where he is currently a Professor. His fields of interest include stochastic dynamics and control. 